\title{
Continuous ambulatory peritoneal dialysis: pharmacokinetics and clinical outcome of paclitaxel and carboplatin treatment
}

\author{
Joan B. Heijns · Maria E. L. van der Burg · Teun van Gelder • \\ Marien W. J. A. Fieren · Peter de Bruijn · Ate van der Gaast • \\ Walter J. Loos
}

Received: 12 November 2007 / Accepted: 21 December 2007/Published online: 19 January 2008

(C) The Author(s) 2008

\begin{abstract}
Purpose Administration of chemotherapy in patients with renal failure, treated with hemodialysis or continuous ambulatory peritoneal dialysis (CAPD) is still a challenge and literature data is scarce. Here we present a case study of a patient on CAPD, treated with weekly and threeweekly paclitaxel/carboplatin for recurrent ovarian cancer. Experimental During the first, second and ninth cycle of treatment, blood, urine and CAPD samples were collected for pharmacokinetic analysis of paclitaxel and total and unbound carboplatin-derived platinum.

Results Treatment was well tolerated by the patient. No excessive toxicity was observed and at the end of treatment she was in a complete remission. The plasma pharmacokinetics of paclitaxel were unaltered compared to historical data, with neglectable urinary and CAPD clearance. In contrast, the pharmacokinetics of carboplatin were altered, with doubled half-lives compared to patients with normal renal function. Of the administered carboplatin dose, up to $20 \%$ was cleared via the dialysate, while only up to $8 \%$ was cleared via the urine.

Conclusion Paclitaxel and carboplatin can be safely administered to patients with chronic renal failure on
\end{abstract}

J. B. Heijns · M. E. L. van der Burg · P. de Bruijn .

A. van der Gaast · W. J. Loos ( $\square)$

Department of Medical Oncology, Erasmus Medical Center,

Daniel den Hoed Cancer Center, University Medical Center,

Room AS-15, Groene Hilledijk 301, 3075 EA Rotterdam,

The Netherlands

e-mail: w.loos@erasmusmc.nl

T. van Gelder · M. W. J. A. Fieren

Department of Internal Medicine, Erasmus Medical Center,

University Medical Center, Rotterdam, The Netherlands
CAPD. For paclitaxel the generally applied dose can be administered, and although for carboplatin dose-adjustment is required due to the diminished renal function, the dose can be calculated using Calvert's formula.

Keywords CAPD - Paclitaxel - Carboplatin · Pharmacokinetic $\cdot$ Ovarian cancer

\section{Introduction}

Platinum-based chemotherapy is commonly accepted as the standard first line treatment for ovarian cancer. Because of a more favorable toxicity profile, carboplatin is frequently preferred over cisplatin [7, 16, 24, 25, 27, 29]. Carboplatin is mainly cleared $(70 \%)$ by renal excretion, with most of the drug excreted unchanged in the urine over the first $24 \mathrm{~h}$ in patients with a normal renal function (i.e., GFR $33-135 \mathrm{~mL} /$ min) [15]. The renal clearance of carboplatin, in patients with a normal renal function, is dependent on the glomerular filtration rate (GFR). Calvert [3] showed in pharmacokinetic studies that the renal clearance of carboplatin is linearly related to the GFR and ever since than carboplatin doses are commonly calculated by Calvert's formula [3] (Eq. 1). In the formula, the drug's exposure, expressed as the area under concentration time curve (AUC), is a set value, depending on the chemotherapy schedule used.

Dose $(\mathrm{mg})=$ Target AUC $(\mathrm{mg} / \mathrm{mL} \times \min )$

$$
\times[\text { GFR }(\mathrm{mL} / \mathrm{min})+25]
$$

Calvert's formula has been developed using data of cancer patients with GFR from 33 to $135 \mathrm{~mL} / \mathrm{min}$, in which the GFR is measured using the ${ }^{51} \mathrm{Cr}$-EDTA clearance. However, due to the expensive and patientinconvenient use of the ${ }^{51} \mathrm{Cr}$-EDTA clearance, the GFR is 
commonly estimated using, among others, the CockcroftGault formula [5]. The substitution of the method for the estimation of the GFR is questionable and results in less predictive estimations of the carboplatin clearance [9] and it is still unknown whether Calvert's formula may also be used for patients with GFR less than $10 \mathrm{~mL} / \mathrm{min}$ and on continuous ambulatory peritoneal dialysis (CAPD).

In ovarian cancer carboplatin is mostly combined with paclitaxel in view of the proven added value of the latter [29]. Paclitaxel is extensively metabolized by hepatic cytochrome P450 enzymes and is mainly cleared by biliary secretion, with less than $10 \%$ excreted by the kidneys [21].

Studies describing the pharmacokinetics of carboplatin and/or paclitaxel in patients with renal failure are scarce [1, $4,6,10,17,19,21,31,32,35-37]$. As paclitaxel is predominantly cleared by hepatic metabolism and biliary excretion, it was concluded that there is no need for dose adjustment of paclitaxel in patients with renal failure [1, 19, 32, 37]. Furthermore, it was shown that Calvert's formula could be safely applied in patients with minimal renal function (i.e., GFR values less than $10 \mathrm{~mL} / \mathrm{min}$ ) and on hemodialysis, in which carboplatin is cleared via the dialysate $[4,12,35]$. In patients on hemodialysis the GFR is set at zero in Calvert's formula (Eq. 1) to calculate the dose, while the hemodialysis is started within $24 \mathrm{~h}$ after the start of infusion [21].

Publications, supporting safe and efficient therapies of (cytotoxic) anticancer agents in patients on CAPD are even more scarce $[12,20,34]$. To the best of our knowledge, to date no reports have been published describing the pharmacokinetics of paclitaxel in patients on CAPD, while the pharmacokinetics of carboplatin have been described in a single pediatric patient on CAPD [12], in which it was concluded that carboplatin was not cleared by peritoneal dialysis.

Here, we report on the pharmacokinetics of carboplatin and paclitaxel in plasma, urine and peritoneal dialysate as well as the clinical data of a patient with recurrent ovarian cancer on CAPD.

\section{Patient and methods}

\section{Patient}

A 49-year-old Caucasian female was diagnosed with ovarian cancer FIGO stage IIIc in 2002. The initial treatment consisted of total abdominal hysterectomy and bilateral salpingo-oophorectomy, omentectomy and resection of all macroscopic tumor lesions. Postoperatively treatment consisted of nine cycles of three-weekly paclitaxel and carboplatin. The patient had preexistent moderate renal failure (creatinine $200 \mu \mathrm{mol} / \mathrm{L}$ ), most probably due to longstanding hypertension. At the end of the treatment a clinical complete remission of the ovarian cancer was observed. During follow-up her renal function deteriorated progressively and in 2004 she developed end-stage renal failure for which chronic ambulatory peritoneal dialysis was started. In 2005 she presented with increasing plasma concentrations of the tumor marker CA 125 and a few months later she had clinical progressive disease with liver, spleen and lung metastases and also retroperitoneal and inguinal lymph nodes metastases.

By that time she dialyzed four times a day, using $2 \mathrm{~L}$ bags of dialysis fluid, in a scheme of twice daily $1.36 \%$ glucose, once $2.27 \%$ glucose, each remaining $4-6 \mathrm{~h}$ in the peritoneal cavity. During the night she used $7.5 \%$ glucose (extraneal), which remained the peritoneal cavity for at least $6 \mathrm{~h}$.

She was then treated with six-weekly cycles of dosedense induction chemotherapy consisting of paclitaxel $90 \mathrm{mg} / \mathrm{m}^{2}$, administered over $1 \mathrm{~h}$, followed by a $1 \mathrm{~h}$ infusion of carboplatin targeted at AUC 4 [2, 33]. At start of therapy, while the patient was continuously treated with peritoneal dialysis, serum creatinine was $778 \mu \mathrm{mol} / \mathrm{L}$.

Subsequently, according to the protocol, in which after induction chemotherapy with dose-dense weekly paclitaxel carboplatin treatment is changed into standard threeweekly paclitaxel carboplatin, she received six cycles of three-weekly paclitaxel $175 \mathrm{mg} / \mathrm{m}^{2}$, administered over $3 \mathrm{~h}$, followed by a $1 \mathrm{~h}$ infusion of carboplatin at AUC 5 . The dose of carboplatin was calculated using Calvert's formula (Eq. 1, [3]) in which the GFR was calculated according to the Cockcroft Gault formula [5]. Pharmacokinetics were performed. Because of renal failure, she was already treated with erythropoietin at a dose of 10,000 IU once a week.

\section{Pharmacokinetic sampling}

For paclitaxel and carboplatin plasma pharmacokinetic analysis, blood samples were collected during the first and second one-weekly cycles and the third three-weekly cycle (i.e. cycle 9) in the presence of lithium heparin as anticoagulant. Samples for paclitaxel analysis were taken at the following time points: before the intravenous infusion, halfway the infusion (i.e., $30 \mathrm{~min}$ during the $1 \mathrm{~h}$ infusion and $1 \mathrm{~h} 30 \mathrm{~min}$ during the $3 \mathrm{~h}$ infusion), at the end of infusion and at $30 \mathrm{~min}, 1,2,4,6$ and $24 \mathrm{~h}$ after the end of infusion. Within 15 min after collection, plasma was separated by centrifugation at 3,000g for $10 \mathrm{~min}$, which was stored at $T<-70^{\circ} \mathrm{C}$ until analysis. For carboplatin analysis, blood samples were collected at the following time 
points: before the intravenous infusion, $30 \mathrm{~min}$ after the start of infusion, at the end of the $1 \mathrm{~h}$ infusion and at 1,2 , 3,4 and $21 \mathrm{~h}$ after the end of infusion. Within $15 \mathrm{~min}$ after collection, plasma was separated by centrifugation at $3,000 \mathrm{~g}$ for $10 \mathrm{~min}$. Subsequently, $500-\mu \mathrm{L}$ aliquots of the plasma supernatant were mixed with $1.0-\mathrm{mL}$ aliquots of ice-cold $\left(-20^{\circ} \mathrm{C}\right)$ ethanol and stored at $T<-20^{\circ} \mathrm{C}$ for a maximum of $24 \mathrm{~h}$. Ethanolic supernatant was collected by centrifugation of the samples at maximum speed in an Eppendorf centrifuge $(23,000 \mathrm{~g})$ for $5 \mathrm{~min}$ after which the clear supernatant was subsequently stored at $T<-70^{\circ} \mathrm{C}$ until analysis. The remaining plasma supernatant, for the analysis of carboplatin-derived total platinum, was stored at $T<-70^{\circ} \mathrm{C}$ until analysis.

Peritoneal dialysis samples were also collected in heparinized containers and stored at $T<-70^{\circ} \mathrm{C}$ until analysis. Samples were collected up to $24 \mathrm{~h}$ after the start of the paclitaxel infusion. The time of dialysis as well as the time in the peritoneal cavity and the weight of each dialysis bag was accurately recorded.

Urine samples, 800-1,150 mL per day, were collected during the same time-period in polypropylene containers, from which aliquots were stored at $T<-70^{\circ} \mathrm{C}$ pending analysis.

\section{Carboplatin analysis}

Plasma concentrations of unbound carboplatin-derived platinum were determined according to a method as described for cisplatin-derived platinum [22]. For unbound platinum analysis, on the day of analysis aliquots of $1,000 \mu \mathrm{L}$ of the ethanolic supernatant were evaporated to dryness under nitrogen at $T=80^{\circ} \mathrm{C}$, and the residue reconstituted in $200 \mu \mathrm{L}$ diluent (i.e., water containing $0.2 \%(\mathrm{v} / \mathrm{v})$ Triton $\mathrm{X}-100$ and $0.06 \%(\mathrm{w} / \mathrm{v})$ cesium chloride). A volume of $20 \mu \mathrm{L}$, in duplicate, was injected onto the graphite furnace of a Perkin Elmer Model $4110 \mathrm{ZL}$ atomic absorption spectrophotometer (Uberlingen, Germany). Platinum peak areas were measured at $265.9 \mathrm{~nm}$. The lower limit of quantitation was established at $0.0300 \mu \mathrm{g} / \mathrm{mL}$ unbound platinum in plasma. For total platinum analysis, plasma aliquots were accurately sixfold diluted in diluent from which subsequently also aliquots of $20 \mu \mathrm{L}$ were injected onto the graphite furnace. The lower limit of quantitation for total carboplatin-derived platinum was established at $0.200 \mu \mathrm{g} / \mathrm{mL}$ in plasma.

Urine samples were analyzed, after a fivefold dilution in blank plasma prior to processing, as for total carboplatinderived platinum as described above.

Aliquots of $25-100 \mu \mathrm{L}$ of peritoneal dialysis samples were evaporated to dryness at $T=80^{\circ} \mathrm{C}$ under nitrogen.
The pellets were subsequently dissolved in $100 \mu \mathrm{L}$ blank plasma and further processed as described above for total carboplatin-derived platinum.

\section{Paclitaxel analysis}

Paclitaxel was quantitated on newly developed and validated methods by liquid chromatography coupled to tandem mass-spectrometric detection (LC-MS/MS), based on a method recently concisely described for docetaxel [11]. Briefly, to $100 \mu \mathrm{L}$ plasma aliquots, $200 \mu \mathrm{L} 100 \mathrm{ng} /$ $\mathrm{mL}$ docetaxel (10 $\mathrm{ng} / \mathrm{mL}$ for the sensitive method) in $100 \%$ acetonitrile was added. Subsequently, an aliquot of $1 \mathrm{~mL}$ $n$-butylchloride was added, where after the samples were vigorously mixed for $10 \mathrm{~min}$. Subsequently, $1 \mathrm{~mL}$ aliquots of supernatant, obtained by centrifugation at $18,000 \mathrm{~g}$ for $10 \mathrm{~min}$, were evaporated under a stream of nitrogen at $T=70^{\circ} \mathrm{C}$. The residues were dissolved in $150 \mu \mathrm{L}$ aliquots of acetonitrile/water/formic acid (40:60:0.1 v/v/v), from which aliquots of $5 \mu \mathrm{L}$ (or $50 \mu \mathrm{L}$ for the sensitive assay) were injected onto an Alltima HP C18 HL $3 \mu \mathrm{m}$ column $(50 \times 2.1 \mathrm{~mm}$ internal diameter, Alltech Applied Science, Breda, the Netherlands). The mobile phase, acetonitrile and water with $0.1 \%$ (v/v) formic acid, was delivered using a linear gradient setting at a flow rate of $0.2 \mathrm{~mL} / \mathrm{min}$ with the percentage of acetonitrile changing from 50 to $100 \%$ in 1 min. A MicroMass Quatro Micro triple-quadropole mass spectrometer [Waters Chromatography B.V. (Etten-Leur, The Netherlands) ] was used for detection in the positive ion mode. The electrospray ionization was set at $3.8 \mathrm{kV}$ and at the cone voltage at $18 \mathrm{~V}$. The collision energies were set at $13 \mathrm{eV}$ for paclitaxel and $18 \mathrm{eV}$ for docetaxel, with the collision gas (argon) pressure set at 0.004 mbar. The dwell time per channel was set at $0.15 \mathrm{~s}$.

Calibration curves were constructed in the range of 20 $1,000 \mathrm{ng} / \mathrm{mL}(2.00-100 \mathrm{ng} / \mathrm{mL}$ for the sensitive assay) by plotting the peak area ratios of paclitaxel $(854.3>286.2)$ to the internal standard docetaxel $(808.3>527.2)$ versus the known paclitaxel concentration with a $1 /$ concentration weight factor. Urine samples were analyzed after dilution in blank human lithium heparinized plasma prior to processing, while peritoneal dialysis samples were processed non-diluted.

Pharmacokinetic data analysis

Individual plasma pharmacokinetic parameters for both total and unbound carboplatin-derived platinum as well as for paclitaxel were estimated using noncompartmental analysis using the software program WinNonLin 5.0 (Pharsight, CA, USA). 


\section{Results}

Clinical

The patient tolerated the treatment well and without severe side-effects or complications. The toxicity of the chemotherapy was limited to uncomplicated bone marrow suppression (see Fig. 1).

No dose reductions of paclitaxel or carboplatin were required during any cycles. Cycles 3 and 5 of the weekly regimen and cycles 5 and 6 of the three-weekly regimen were delayed with one week due to thrombocytopenia CTC grade 2 and or leucocytopenia CTC grade 3. Despite use of erythropoietin, which she already received prior to the start of chemotherapy for her renal anemia, hemoglobin levels decreased to a minimum of $4.2 \mathrm{mmol} / \mathrm{L}$, because of which
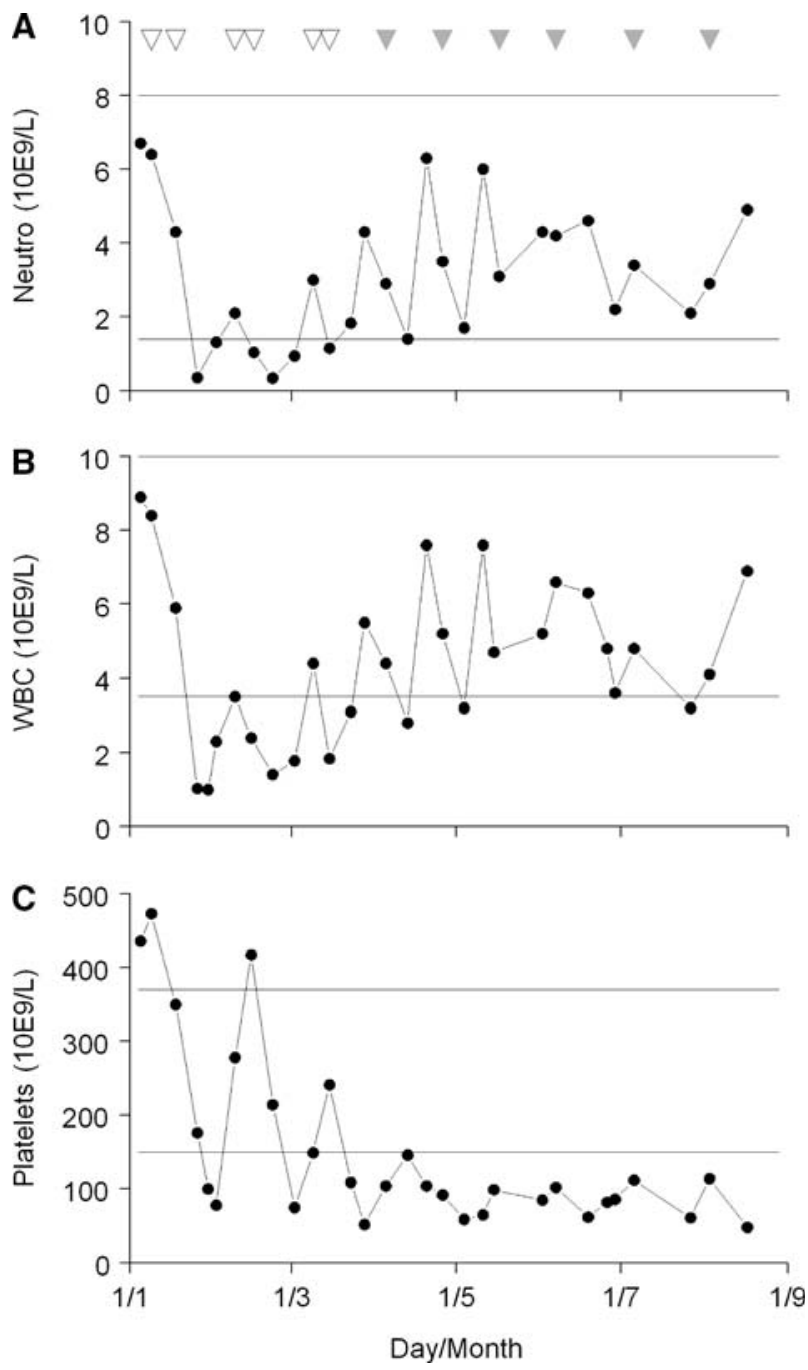

Fig. 1 Absolute neutrophil (a), white blood cell (b) and platelet (c) count during treatment. The solid lines represent the upper and lower limits of normal values. The triangles indicate the treatment days in the weekly schedule (open symbols) and the three-weekly (closed symbols) schedule red blood cell transfusions were given after the fourth and sixth-weekly cycle and after the first, third and fifth threeweekly cycle.

Except for alopecia CTC grade 2, no other non-hematological toxicities were observed. The preexistent CTC grade 1 neurotoxicity remained stable during treatment.

After the induction therapy with six-weekly paclitaxel/ carboplatin cycles a partial remission was achieved and at the end of the three-weekly treatment the patient was in a complete clinical remission. Serum CA 125 normalized from 777 to $22 \mathrm{KU} / \mathrm{L}$. After a progression free interval of 17 months the patient had a recurrence, which was once more successfully retreated with weekly paclitaxel and carboplatin.

\section{Pharmacokinetics}

In Table 1 a summary of the pharmacokinetic data of carboplatin-derived total and unbound platinum as well as of paclitaxel are presented, and in Fig. 2 the pharmacokinetic profiles of the compounds in plasma are shown. The plasma pharmacokinetics of the 1- and 3-h infusion of paclitaxel are comparable to those in patients with normal renal function $[13,28,30]$. Paclitaxel was excreted only for approximately $0.15 \%$ via the urine and $0.048 \%$ via the peritoneal dialysate.

In contrast, the plasma pharmacokinetics of carboplatinderived platinum were different from historical data [8, 23 ]. Both unbound and total platinum showed slow clearances of approximately 21 and $10 \mathrm{~mL} / \mathrm{min}$, respectively and prolonged half-lives. During the first $24 \mathrm{~h}$ after administration, $14-20 \%$ of the administered dose of carboplatin was excreted in the peritoneal fluid, with peritoneal clearances in the range of $3.14-4.03 \mathrm{~mL} / \mathrm{min}$. Carboplatin was excreted for only 6-8\% via the kidneys, with renal clearances in the range of $1.32-1.56 \mathrm{~mL} / \mathrm{min}$.

\section{Discussion}

This case study describes the pharmacokinetics of carboplatin and paclitaxel in an adult cancer patient with endstage renal failure, treated with CAPD. Studies as reported here are of major importance for clinical oncology practice, as (pharmacokinetic guided) clinical studies in patients on substitution therapy for renal failure are scarce.

Paclitaxel, as shown in this report, can be safely administered to patients on CAPD. The observed plasma pharmacokinetics in the studied patient on CAPD were comparable to those in patients with normal renal function $[13,28,30]$ and are in agreement with earlier reports of patients with renal failure treated with paclitaxel $[1,18,19$, 
Table 1 Pharmacokinetic data of carboplatin-derived platinum and paclitaxel

\begin{tabular}{|c|c|c|c|}
\hline Parameter & Course 1 & Course 2 & Course 9 \\
\hline \multicolumn{4}{|c|}{ Carboplatin-derived total platinum } \\
\hline Target AUC (mg min/mL) & 4 & 4 & 5 \\
\hline Carboplatin dose $(\mathrm{mg})^{\mathrm{a}}$ & 130 & 130 & 150 \\
\hline Platinum dose (mg) & 68 & 68 & 79 \\
\hline$C_{\max }(\mu \mathrm{g} / \mathrm{mL})$ & 4.84 & 4.98 & 5.12 \\
\hline $\operatorname{AUC}_{0-\text { inf }}(\mu \mathrm{g} \mathrm{h} / \mathrm{mL})$ & 106 & 119 & 137 \\
\hline $\mathrm{CL}(\mathrm{mL} / \mathrm{min})$ & 10.6 & 9.6 & 9.6 \\
\hline$T 1 / 2_{\mathrm{z}}(\mathrm{h})$ & 17.6 & 19.6 & 19.3 \\
\hline \multicolumn{4}{|c|}{ Carboplatin-derived unbound platinum } \\
\hline$C_{\max }(\mu \mathrm{g} / \mathrm{mL})$ & 3.93 & 3.66 & 4.67 \\
\hline $\operatorname{AUC}_{0 \text {-inf }}(\mu \mathrm{g} \mathrm{h} / \mathrm{mL})$ & 51.6 & 54.2 & 67.7 \\
\hline $\mathrm{AUC}_{0 \text {-inf }}(\mathrm{mg} \min / \mathrm{mL})^{\mathrm{b}}$ & 5.89 & 6.19 & 7.73 \\
\hline $\mathrm{CL}(\mathrm{mL} / \mathrm{min})$ & 22.0 & 20.9 & 19.4 \\
\hline$T 1 / 2_{\mathrm{z}}(\mathrm{h})$ & 10.5 & 11.7 & 10.4 \\
\hline Urine $(\%)$ & 6.0 & 6.4 & 8.0 \\
\hline $\mathrm{CL}_{\text {urine }}(\mathrm{mL} / \mathrm{min})^{\mathrm{c}}$ & 1.32 & 1.34 & 1.56 \\
\hline Peritoneal dialysis $(\%)$ & 14.3 & 19.3 & 20.1 \\
\hline $\mathrm{CL}_{\text {peritoneal dialysis }}(\mathrm{mL} / \mathrm{min})^{\mathrm{c}}$ & 3.14 & 4.03 & 3.37 \\
\hline \multicolumn{4}{|l|}{ Paclitaxel } \\
\hline Dose $\left(\mathrm{mg} / \mathrm{m}^{2}\right)$ & 90 & 90 & 175 \\
\hline Dose (mg) & 140 & 140 & 270 \\
\hline$C_{\max }(\mu \mathrm{g} / \mathrm{mL})$ & 3.71 & 2.43 & 3.26 \\
\hline $\operatorname{AUC}_{0-\text { inf }}(\mu \mathrm{g} \mathrm{h} / \mathrm{mL})$ & 6.39 & 6.07 & 11.7 \\
\hline $\mathrm{CL}(\mathrm{mL} / \mathrm{min})$ & 365 & 384 & 385 \\
\hline$T 1 / 2_{\mathrm{z}}(\mathrm{h})$ & 9.1 & 9.9 & 7.8 \\
\hline Urine $(\%)$ & 0.16 & 0.15 & 0.16 \\
\hline $\mathrm{CL}_{\text {urine }}(\mathrm{mL} / \mathrm{min})^{\mathrm{d}}$ & 0.57 & 0.59 & 0.60 \\
\hline Peritoneal dialysis $(\%)$ & 0.047 & 0.048 & 0.049 \\
\hline $\mathrm{CL}_{\text {peritoneal dialysis }}(\mathrm{mL} / \mathrm{min})^{\mathrm{d}}$ & 0.17 & 0.18 & 0.47 \\
\hline
\end{tabular}

a Dose calculated according to Eq. 1

b AUC of carboplatin (in stead of platinum) as expressed by Calvert et al. [3]

${ }^{\mathrm{c}} \mathrm{CL}=$ total amount excreted in urine (or peritoneal dialysate)/AUC unbound carboplatin-derived platinum in plasma

${ }^{\mathrm{d}} \mathrm{CL}=$ total amount excreted in urine (or peritoneal dialysate)/AUC paclitaxel in plasma

26, 32, 35-37]. As paclitaxel is mainly cleared by biliary secretion, following extensive metabolism by hepatic cytochrome $\mathrm{P} 450$ enzymes, and also in patients with normal renal function less than $10 \%$ is excreted by the kidneys [21], dose-adjustments in patients with renal dysfunction are not required. In addition, as shown earlier by Gelderblom et al. [14], paclitaxel hardly distributes into the peritoneal cavity, with $<1.3 \%$ of systemic concentrations found in ascites, which is in agreement with the neglectable clearance of paclitaxel via peritoneal dialysis as reported here.

In contrast to paclitaxel, the pharmacokinetics of carboplatin-derived platinum in plasma were altered compared
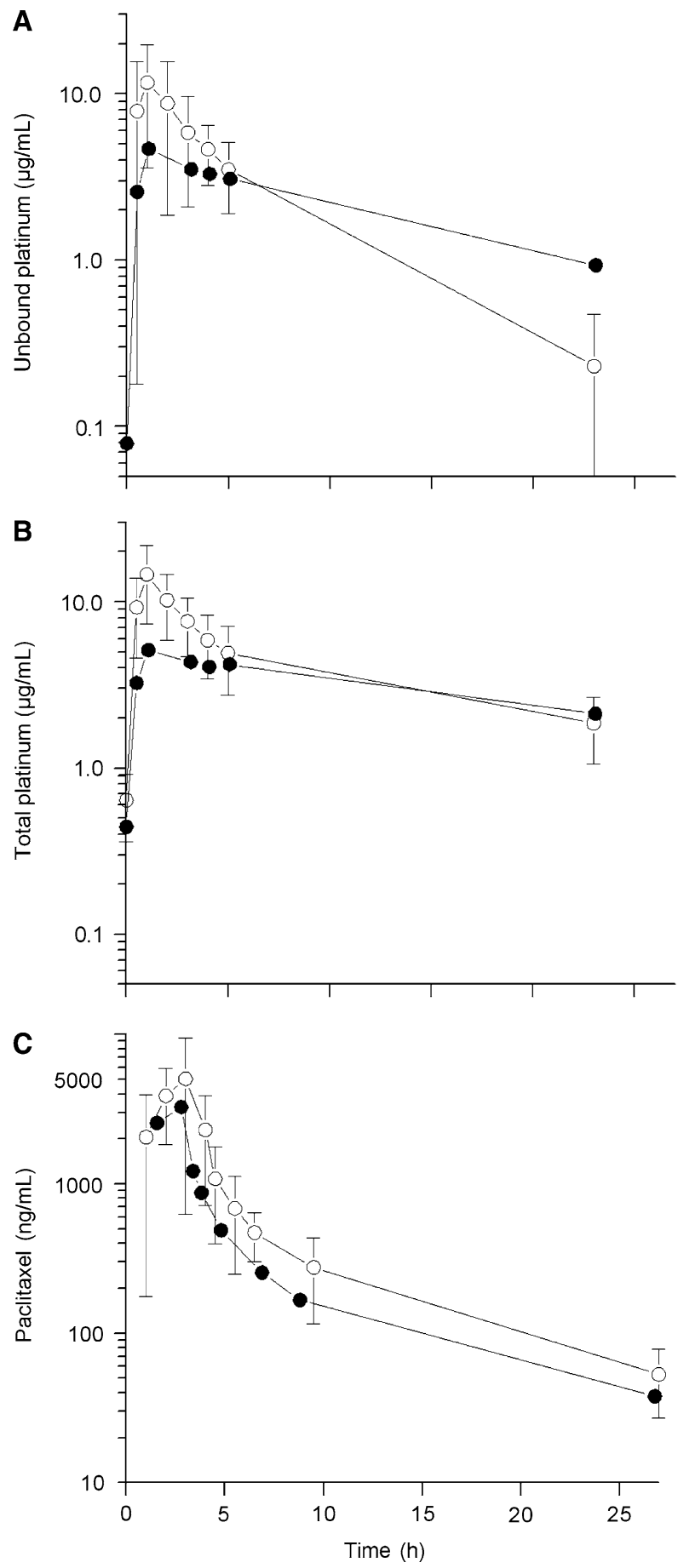

Fig. 2 Plasma concentration time curves of carboplatin-derived unbound (a) and total (b) platinum and of paclitaxel (c). Closed symbols show the data of course nine of the studied patient. Open symbols represent data (mean $\pm 2 \mathrm{SD}$ ) of a reference population of patients with normal renal function treated at our institute $(n=12$ for $1 \mathrm{~h}$ carboplatin infusion dosed at AUC $5 ; n=5$ for $3 \mathrm{~h}$ paclitaxel infusion dosed at $175 \mathrm{mg} / \mathrm{m}^{2}$ )

to the pharmacokinetics in patients with normal renal function $[8,23]$. The half-lifves of total and unbound platinum, as estimated during the first $24 \mathrm{~h}$, were almost 
doubled with total and unbound platinum quantifiable up to 7 days after administration. Although the half-life of unbound platinum was doubled, the estimated AUC of unbound carboplatin in the three studied courses was no more than 1.5 times the target AUC. The higher observed AUCs of unbound carboplatin-derived platinum might be a result of a slight overestimation of the GFR value. The GFR value may be overestimated in patients on dialysis as the observed plasma creatinine concentrations are determined by the sum of the urinary and peritoneal dialysis clearances. In contrast to glomerular filtration the clearance via the dialysis is purely gradient driven and depends on the molecular weight of the compound. By setting the GFR value at zero however, the contribution of the peritoneal clearance and the (remaining) residual kidney function would have been neglected and as a result the carboplatin dose would have been underestimated. In addition, the slow clearance and prolonged half-life of carboplatin did not lead to dose limiting toxicities. Peritoneal dialysis cleared 14$20 \%$ of the administered dose during the first $24 \mathrm{~h}$, while the kidneys cleared 6-8\% in the same time period. In patients with a normal renal function or on hemodialysis, approximately $70 \%$ of the dose is cleared via the kidneys or hemodialysate $[6,17,21,31]$. The observed $20 \%$ clearance of carboplatin via peritoneal dialysis in the studied patient is high in contrast to an earlier study of English et al. [12] in which carboplatin was not cleared via peritoneal dialysis, as stated by the authors. The discrepancy might be related to the fact that in our study, a continuous peritoneal dialysis was applied, while in the study of English et al. [12], the peritoneal dialysis was only applied from 5 to $14 \mathrm{~h}$ after the start of the carboplatin infusion. Moreover, in the study of English et al. [12], still 30\% of the administered carboplatin dose was cleared via the kidneys, in contrast to only $6-8 \%$ in our studied patient [12].

In conclusion, paclitaxel and carboplatin can be safely administered to patients with chronic renal failure and on CAPD. Paclitaxel can be administered at therapeutic doses applied to patients with normal renal function. For carboplatin, dose-adjustments are required, however yet the doses can be calculated using Calvert's formula [3].

Open Access This article is distributed under the terms of the Creative Commons Attribution Noncommercial License which permits any noncommercial use, distribution, and reproduction in any medium, provided the original author(s) and source are credited.

\section{References}

1. Balat O, Kudelka AP, Edwards CL, Verschraegen C, Mante R, Kavanagh JJ (1996) A case report of paclitaxel administered to a patient with platinum-refractory ovarian cancer on long-term hemodialysis. Eur J Gynaecol Oncol 17:232-233
2. Cadron I, Leunen K, Amant F, Van Gorp T, Neven P, Vergote I (2007) The "Leuven" dose-dense paclitaxel/carboplatin regimen in patients with recurrent ovarian cancer. Gynecol Oncol 106:354-361

3. Calvert AH, Newell DR, Gumbrell LA, O'Reilly S, Burnell M, Boxall FE, Siddik ZH, Judson IR, Gore ME, Wiltshaw E (1989) Carboplatin dosage: prospective evaluation of a simple formula based on renal function. J Clin Oncol 7:1748-1756

4. Chatelut E, Rostaing L, Gualano V, Vissac T, De Forni M, TonThat H, Suc JM, Houin G, Canal P (1994) Pharmacokinetics of carboplatin in a patient suffering from advanced ovarian carcinoma with hemodialysis-dependent renal insufficiency. Nephron 66:157-161

5. Cockcroft DW, Gault MH (1976) Prediction of creatinine clearance from serum creatinine. Nephron 16:31-41

6. Dagher R, Kreissman S, Robertson KA, Provisor A, Bergstein J, Burke K, Rodman JH, Emanuel D, Smith FO (1998) High dose chemotherapy with autologous peripheral blood progenitor cell transplantation in an anephric child with multiply recurrent Wilms tumor. J Pediatr Hematol Oncol 20:357-360

7. du Bois A, Luck HJ, Meier W, Mobus V, Costa S, Richter B, Warm M, Bauknecht T, Schroder W, Olbricht S, Nitz U, Jackisch C (1997) Carboplatin/paclitaxel versus cisplatin/paclitaxel as first-line chemotherapy in advanced ovarian cancer: an interim analysis of a randomized phase III trial of the Arbeitsgemeinschaft Gynakologische Onkologie Ovarian Cancer Study Group. Semin Oncol 24:S15-44-S15-52

8. Duffull SB, Robinson BA (1997) Clinical pharmacokinetics and dose optimisation of carboplatin. Clin Pharmacokinet 33:161183

9. Ekhart C, de Jonge ME, Huitema AD, Schellens JH, Rodenhuis S, Beijnen JH (2006) Flat dosing of carboplatin is justified in adult patients with normal renal function. Clin Cancer Res 12:65026508

10. el-Yazigi A, Alfurayh O, Amer M (1995) Pharmacokinetics of carboplatin in a patient with cervical cancer with ureteric obstruction before, during, and after hemodialysis. J Clin Pharmacol 35:1003-1007

11. Engels FK, Mathot RA, Loos WJ, van Schaik RH, Verweij J (2006) Influence of high-dose ketoconazole on the pharmacokinetics of docetaxel. Cancer Biol Ther 5:833-839

12. English MW, Lowis SP, Peng B, Boddy A, Newell DR, Price L, Pearson AD (1996) Pharmacokinetically guided dosing of carboplatin and etoposide during peritoneal dialysis and haemodialysis. Br J Cancer 73:776-780

13. Gelderblom H, Mross K, ten Tije AJ, Behringer D, Mielke S, van Zomeren DM, Verweij J, Sparreboom A (2002) Comparative pharmacokinetics of unbound paclitaxel during 1- and 3-hour infusions. J Clin Oncol 20:574-581

14. Gelderblom H, Verweij J, van Zomeren DM, Buijs D, Ouwens L, Nooter K, Stoter G, Sparreboom A (2002) Influence of Cremophor El on the bioavailability of intraperitoneal paclitaxel. Clin Cancer Res 8:1237-1241

15. Go RS, Adjei AA (1999) Review of the comparative pharmacology and clinical activity of cisplatin and carboplatin. J Clin Oncol 17:409-422

16. Gore ME, Fryatt I, Wiltshaw E, Dawson T (1990) Treatment of relapsed carcinoma of the ovary with cisplatin or carboplatin following initial treatment with these compounds. Gynecol Oncol 36:207-211

17. Inoue A, Saijo Y, Kikuchi T, Gomi K, Suzuki T, Maemondo M, Miki M, Sato T, Nukiwa T (2004) Pharmacokinetic analysis of combination chemotherapy with carboplatin and etoposide in small-cell lung cancer patients undergoing hemodialysis. Ann Oncol 15:51-54 
18. Jeyabalan N, Hirte HW, Moens F (2000) Treatment of advanced ovarian carcinoma with carboplatin and paclitaxel in a patient with renal failure. Int J Gynecol Cancer 10:463-468

19. Kawate S, Takeyoshi I, Morishita Y (2006) Pharmacokinetics of paclitaxel in a hemodialysis patient with advanced gastric cancer: a case report. World J Gastroenterol 12:5237-5239

20. Lee CW, Fabbro J (2005) Administration of cisplatin and etoposide during chronic ambulatory peritoneal dialysis. Clin Oncol (R Coll Radiol) 17:667

21. Li YF, Fu S, Hu W, Liu JH, Finkel KW, Gershenson DM, Kavanagh JJ (2007) Systemic anticancer therapy in gynecological cancer patients with renal dysfunction. Int J Gynecol Cancer 17:739-763

22. Loos WJ, de Jongh FE, Sparreboom A, de Wit R, van Boven-van Zomeren DM, Stoter G, Nooter K, Verweij J (2006) Evaluation of an alternate dosing strategy for cisplatin in patients with extreme body surface area values. J Clin Oncol 24:1499-1506

23. Mita C, Chatelut E, Bekradda M, Soulie P, Canal P, Misset JL, Cvitkovic E, Bugat R (2003) Phase I and pharmacological study of an oxaliplatin and carboplatin combination in advanced malignancies. Ann Oncol 14:1776-1782

24. Muggia FM, Braly PS, Brady MF, Sutton G, Niemann TH, Lentz SL, Alvarez RD, Kucera PR, Small JM (2000) Phase III randomized study of cisplatin versus paclitaxel versus cisplatin and paclitaxel in patients with suboptimal stage III or IV ovarian cancer: a gynecologic oncology group study. J Clin Oncol 18:106-115

25. Neijt JP, Engelholm SA, Tuxen MK, Sorensen PG, Hansen M, Sessa C, de Swart CA, Hirsch FR, Lund B, van Houwelingen HC (2000) Exploratory phase III study of paclitaxel and cisplatin versus paclitaxel and carboplatin in advanced ovarian cancer. J Clin Oncol 18:3084-3092

26. Niikura H, Koizumi T, Ito K, Okamura K, Yaegashi N (2003) Carboplatin-based chemotherapy in patients with gynecological malignancies on long-term hemodialysis. Anticancer Drugs 14:735-738

27. Ozols RF, Bundy BN, Greer BE, Fowler JM, Clarke-Pearson D, Burger RA, Mannel RS, DeGeest K, Hartenbach EM, Baergen R (2003) Phase III trial of carboplatin and paclitaxel compared with cisplatin and paclitaxel in patients with optimally resected stage
III ovarian cancer: a Gynecologic Oncology Group study. J Clin Oncol 21:3194-3200

28. Polee MB, Sparreboom A, Eskens FA, Hoekstra R, van de Schaaf J, Verweij J, Stoter G, van der Gaast A (2004) A phase I and pharmacokinetic study of weekly paclitaxel and carboplatin in patients with metastatic esophageal cancer. Clin Cancer Res 10:1928-1934

29. Salzberg M, Thurlimann B, Bonnefois H, Fink D, Rochlitz C, von Moos R, Senn H (2005) Current concepts of treatment strategies in advanced or recurrent ovarian cancer. Oncology 68:293-298

30. Smorenburg CH, Sparreboom A, Bontenbal M, Stoter G, Nooter K, Verweij J (2003) Randomized cross-over evaluation of bodysurface area-based dosing versus flat-fixed dosing of paclitaxel. J Clin Oncol 21:197-202

31. Suzuki S, Koide M, Sakamoto S, Matsuo T (1997) Pharmacokinetics of carboplatin and etoposide in a haemodialysis patient with Merkel-cell carcinoma. Nephrol Dial Transplant 12:137-140

32. Tomita M, Kurata H, Aoki Y, Tanaka K, Kazama JJ (2001) Pharmacokinetics of paclitaxel and cisplatin in a hemodialysis patient with recurrent ovarian cancer. Anticancer Drugs 12:485487

33. van der Burg ME, van der Gaast A, Vergote I, Burger CW, van Doorn HC, de Wit R, Stoter G, Verweij J (2005) What is the role of dose-dense therapy? Int J Gynecol Cancer 15(suppl 3):233240

34. Wallach RC, Kabakow B, Blinick G (1976) Intravenous chemotherapy with concurrent peritioneal dialysis: continued treatment of ovarian carcinoma after drug toxicity. Gynecol Oncol 4:299-306

35. Watanabe M, Aoki Y, Tomita M, Sato T, Takaki Y, Kato N, Kikuchi M, Kase H, Tanaka K (2002) Paclitaxel and carboplatin combination chemotherapy in a hemodialysis patient with advanced ovarian cancer. Gynecol Oncol 84:335-338

36. Woo MH, Gregornik D, Shearer PD, Meyer WH, Relling MV (1999) Pharmacokinetics of paclitaxel in an anephric patient. Cancer Chemother Pharmacol 43:92-96

37. Yokoyama Y, Futagami M, Higuchi T, Mizunuma H (2006) Pharmacokinetic analysis of paclitaxel and carboplatin in a patient with advanced ovarian cancer during hemodialysis-case report. Eur J Gynaecol Oncol 27:437-439 